\title{
Development of Taste Masked Orodispersible Film Containing Paroxetine Hydrocloride
}

\author{
Swapnila Vivek Shinde*, Shraddha Phatak, Ganesh Awale, Supriya Nikam \\ Department of Pharmaceutics, Sinhgad Institute of Pharmacy, Narhe, Pune, Maharashtra, INDIA.
}

\begin{abstract}
Aim and Objectives: The present study was to formulate and evaluate orodispersible films to overcome drawbacks of conventional dosage forms such as degradation by first-pass hepatic metabolism, decreased bioavailability and patient non-compliance. In the present work the taste masked Paroxetine $\mathrm{HCl}$ was formulated in the form of Orodispersible film. Rationale for formulating the taste masked PXT in ODF form was to increase convenience of paediatric, geriatric, bedridden, psychiatric patients and those who have dysphasia. Materials and Methods: The orodispersible films were prepared by solvent casting method using HPMC E-5, Propylene glycol (plasticizer), citric acid (saliva stimulating agent), stevioside (sweetener) and PVP K-30 as superdisintegrant. Paroxetine hydrochloride was taste masked by inclusion complex formation with HP $\beta-C D$ by freeze drying. The 3 factorial designs was used to study the effect of independent variables viz. concentration of HPMC E-5 (X) and concentration of PG (X) on three dependent variables such as in vitro drug release, folding endurance and disintegration time. Optimized formulation was evaluated for physical appearance, thickness, moisture content, weight uniformity, surface $\mathrm{pH}$ measurement and taste masking ability by human gustatory sensation test. Results: The optimized batch (F3) showed $99.94 \%$ drug release with 72 as folding endurance and disintegration time of 24 sec. Ex vivo permeation, oral mucosa sensitivity test, release kinetics and accelerated stability studies confirmed that developed formulation exhibited flash drug release and was stable, non-irritant and therapeutically effective. Conclusion: Taste masked complex of paroxetine hydrochloride with HP $\beta-C D$ could be successfully formulated into orodispersible film.

Key words: Paroxetine hydrochloride, Hydroxy Propyl Beta Cyclodextrin, Taste-masking, Freeze-drying, Oral films.
\end{abstract}

\section{INTRODUCTION}

Development of drug delivery to any molecule is based on market needs, product differentiation and patient compliance. In the present scenario, there is an ever increasing demand for more patientcompliant dosage forms. One important innovation in this direction is fast dissolving/ disintegrating dosage forms. These have been proved ideal for the geriatric and paediatric populations, bedridden or travelling patients, people suffering from dysphasia, clinical conditions in which water intake is limited and situations in which water is not available. Rapidly disintegrating/dissolving dosage forms are further categorized as Orodispersible
Tablets (ODTs) and Orodispersible Films (ODFs). Most ODTs are fragile and brittle, need special package for protection during storage and transportation. However, films are flexible; they are not as fragile as ODTs, easy for transportation, handling and storage. ${ }^{1}$

ODF is a dosage form that employs hydrophilic polymer which allows the dosage form to quickly hydrate by saliva and / or adhere to mucosa, disintegrate within a few seconds, dissolve and releases medication for oromucosal absorption when placed on the tongue or oral cavity. ${ }^{2}$ The oral mucosa is relatively permeable due to thin membrane and large veins. It gives rapid absorption and instant bioavailability of
Submission Date: 18-06-2019; Revision Date: 06-02-2020; Accepted Date: 30-04-2020

DOI: 10.5530/ijper.54.2s.66 Correspondence: Dr. Swapnila Vivek Shinde Department of Pharmaceutics, Sinhgad Institute of Pharmacy, Narhe, Pune-411 041, Maharashtra, INDIA.

Phone: +91-020-66831802

E-mail: swapnila84@rediffmail.com

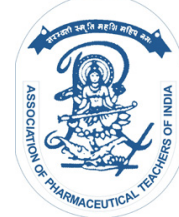

www.ijper.org 
drugs due to high blood flow. ${ }^{3}$ ODF was developed based on the technology of transdermal patch and is specially designed for the drugs which have extensive first pass metabolism and low dose. There are many methods for formulation of rapidly disintegrating/ dissolving films. Practically reviewing these methods with respect to the ease of preparation and costeffectiveness, the solvent casting method was found to be the best option. ${ }^{4}$ Cyclodextrins (CD) are cyclic oligosaccharides with a hydrophilic outer surface and a lipophilic central cavity. On account of their relatively hydrophobic interiors, CDs have the ability to form inclusion complexes with a wide range of substrates (Loftson et al. 1996). This complex forming ability of $\mathrm{CD}$ have been widely exploited in the pharmaceutical field for various applications, including taste-masking of bitter drugs. ${ }^{5,6}$ Paroxetine hydrochloride (PXT) is a BCS Class-II drug with very bitter taste. Paroxetine hydrochloride is a SSRI drug generally indicated for the treatment of depression and anxiety and it is extensively metabolized, predominantly due to hepatic metabolism. At present, there is no ODF in the market; the drug is marketed as conventional tablets, sustainedrelease tablets, oral suspensions. Formulation of taste masked ODF of PXT will show rapid onset of action and avoid hepatic metabolism. ${ }^{6,7}$

\section{MATERIALS AND METHODS Materials}

Paroxetine hydrochloride was a generous gift from Zydus Cadila Healthcare Ltd. (Ahmedabad, India). Hydroxy Propyl $\beta$-cyclodextrin (HP $\beta$-CD) was purchased from Loba Chemicals (Mumbai, India). HPMC E-5, PG, PVP K-30, Vanilla flavour and Citric acid were procured from Research Lab Fine Chemicals (Mumbai, India). Stevioside was purchased from Desle Agro export (Pune, India). All reagents were of analytical grade. Double distilled water was used for all the experiments.

\section{Taste masking of Paroxetine $\mathrm{HCl}$ using inclusion complexation}

Phase solubility studies were carried out at room temperature and in triplicate. ${ }^{8}$ An excess amount of paroxetine hydrochloride was added to double distilled water containing various concentrations of HP $\beta$-CD $(0.002-0.1 \mathrm{M})$ in a series of stoppered conical flasks and then shaken for 3 days on a rotary flask shaker. The suspensions were filtered through Whatman filter paper and assayed for Paroxetine hydrochloride using a UV spectrophotometer (Jasco, Japan) at $292.5 \mathrm{~nm}$ against blank prepared using same concentration of HP $\beta$-CD in double distilled water. The association constant $(\mathrm{Ka})$ was calculated from the slope of the linear portion of the phase solubility diagram. According to Equation (1),

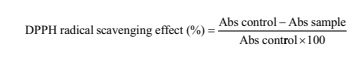

\section{Preparation of solid complexes by freeze-drying method}

Physical mixture of paroxetine hydrochloride and HP $\beta$-CD in a molar ratio of $1: 1$ were added to double distilled water and stirred for $5 \mathrm{hr}$ using magnetic stirrer. The suspension was freeze-dried (Labconco ${ }^{\circledR}$ Freeze Dryer). The freeze-dried complex was pulverized and sieved through $(<38 \mu \mathrm{m}) .^{5}$

\section{Evaluation of taste of complexes}

The sample of drug-HP $\beta$-CD complex (1:1 molar ratio) underwent gustatory sensory evaluation by a panel of five members; the evaluation was performed by classifying the bitter taste into the following five classesClass 5: Very strong bitter, Class 4: Strong bitter,

Class 3: Moderately bitter, Class 2: Slightly bitter, Class 1: No bitter taste/ tasteless.

The pure drug was used as a standard control, with a mean bitter taste of class 4 . Each of the members was given the control, i.e., $10 \mathrm{mg}$ of pure drug and complex (equivalent to $10 \mathrm{mg}$ PXT) to be held in the mouth for 5-10 s then spat out and the bitterness level was recorded. ${ }^{5}$ The members of the panel were asked to gargle and wait for 20 min before another sample was given to them. The mean bitterness value of each complex was calculated based upon the level of bitterness sensed by each individual member of the panel.

\section{Characterization of drug and HP $\beta-C D$ complex}

Evaluation of taste masked drug and HP $\beta$-CD complex prepared by freeze dried method was done using following techniques.

\section{Drug content}

A drug- HP $\beta$-CD complex equivalent to $10 \mathrm{mg}$ of the drug was stirred with $100 \mathrm{ml}$ of acetate buffer $\mathrm{pH} 4.5$ for $60 \mathrm{~min}$. The solution was then filtered and treated as a stock solution $(100 \mu \mathrm{g} / \mathrm{ml}$ of the drug). From this stock solution, the concentration of $10 \mu \mathrm{g} / \mathrm{ml}$ was prepared. Drug content was determined using calibration curve of the pure drug in acetate buffer $\mathrm{pH} 4.5$ spectrophotometrically at $292.5 \mathrm{~nm} .^{5}$

\section{In vitro dissolution study}


Table 1: Composition of taste masked PXT orodispersible film

\begin{tabular}{|c|c|c|c|c|c|c|c|c|c|c|}
\hline \multirow{2}{*}{ Sr. No. } & Name of excipients & \multicolumn{9}{|c|}{ Formulation Code Concentration (\%w/w) } \\
\cline { 3 - 12 } & & F1 & F2 & F3 & F4 & F5 & F6 & F7 & F8 & F9 \\
\hline 1 & HPMC E-5 LV & 59 & 59 & 59 & 61 & 61 & 61 & 63 & 63 & 63 \\
\hline 2 & PG & 32 & 34 & 36 & 32 & 34 & 36 & 32 & 34 & 36 \\
\hline 3 & PVP K-30 & 10 & 10 & 10 & 10 & 10 & 10 & 10 & 10 & 10 \\
\hline 4 & Citric acid & 3 & 3 & 3 & 3 & 3 & 3 & 3 & 3 & 3 \\
\hline 5 & Stevioside & 10 & 10 & 10 & 10 & 10 & 10 & 10 & 10 & 10 \\
\hline 6 & Vanilla flavor & q.s. & q.s. & q.s. & q.s. & q.s. & q.s. & q.s. & q.s. & q.s. \\
\hline
\end{tabular}

Dissolution study of inclusion complex was performed using USP type II apparatus (Electro lab) in $500 \mathrm{ml}$ of acetate buffer $\mathrm{pH}$ 4.5. Temperature was maintained at $37 \pm 0.5^{\circ} \mathrm{C}$ and rotation speed was $50 \mathrm{rpm}$. Samples were withdrawn at time intervals of 2, 4, 6, 8, 10 and $30 \mathrm{~min}$ and analyzed spectrophotometrically at $292.5 \mathrm{~nm}$

\section{Infrared Spectroscopy}

Infrared (IR) spectra of pure drug, HP $\beta$-CD and complex were obtained by using IR spectrophotometer (Jasco, Japan) with $\mathrm{KBr}$ pellets. The scanning range used was 4000 to $400 \mathrm{~cm}^{-1}$.

\section{X-ray Diffractometry}

Drug (Paroxetine $\mathrm{HCl}$ ) and complex of drug with $\mathrm{HP}$ $\beta$-CD were subjected to powder X-Ray Diffraction (XRD).

\section{Differential scanning calorimetry (DSC)}

DSC was performed to confirm the complexation between drug and HP $\beta$-CD. Wherein small amount of sample $(5.09 \mathrm{mg})$ was hermetically sealed and analyzed using DSC 60 (Shimadzu, Japan). Thermograms of complex and pure drug were compared for confirmation of complex formation.

\section{Preparation of orodispersible films}

Accurately weighed freeze dried complex of PXT $+\mathrm{HP}$ $\beta$-CD (equivalent to $110.73 \mathrm{mg}$ of PXT) was dissolved in $10 \mathrm{ml}$ of distilled water using magnetic stirrer for 30 min. Further required quantity of PVP K-30, Citric acid and Stevioside were added with constant stirring into same solution. HPMC E-5 LV was dissolved in $10 \mathrm{ml}$ of cold DW separately (since HPMC dissolves in cold water) for 2-3 hr. Both the solutions were mixed together followed by addition of propylene glycol $(33-35 \% \mathrm{w} / \mathrm{w}$ of polymers) using magnetic stirrer (Equip-Tronics, Mumbai) with constant stirring for 10-15 min. This solution was sonicated for $30 \mathrm{~min}$. The resultant clear, bubble-free solution was casted on glass Petri plate and allowed to dry in hot air oven at $40^{\circ} \mathrm{C}$

\begin{tabular}{|c|c|c|c|c|}
\hline \multirow{2}{*}{$\begin{array}{c}\text { Batch } \\
\text { No. }\end{array}$} & \multicolumn{2}{|c|}{ Coded levels } & \multicolumn{2}{|c|}{ Actual level } \\
\hline & $\begin{array}{l}\text { Factor } 1 \\
\left(X_{1}\right)\end{array}$ & $\begin{array}{c}\text { Factor } 2 \\
\left(\mathrm{X}_{2}\right)\end{array}$ & $\begin{array}{l}\text { Factor } 1 \\
\text { (Conc. of } \\
\text { HPMC E-5) }\end{array}$ & $\begin{array}{c}\text { Factor } 2 \\
\text { (Conc. of } \\
\text { PG) }\end{array}$ \\
\hline F1 & -1 & -1 & 59 & 32 \\
\hline F2 & -1 & 0 & 59 & 34 \\
\hline F3 & -1 & +1 & 59 & 36 \\
\hline F4 & 0 & -1 & 61 & 32 \\
\hline F5 & 0 & 0 & 61 & 34 \\
\hline F6 & 0 & +1 & 61 & 36 \\
\hline F7 & +1 & -1 & 63 & 32 \\
\hline F8 & +1 & 0 & 63 & 34 \\
\hline F9 & +1 & +1 & 63 & 36 \\
\hline
\end{tabular}

for $12 \mathrm{hr}^{9}{ }^{9}$ Finally, dried film was cut into the size of $3 \mathrm{~cm} \times 2 \mathrm{~cm}$, with total surface area of $6 \mathrm{~cm}^{2}$. Samples were packed in aluminium foil and stored in amber colored glass container at room temperature and $60 \% \mathrm{RH} .{ }^{10}$

\section{Design of experiments}

A $3^{2}$ randomized full factorial design was applied to the experiments. Concentration (\%) of HPMC E-5 LV and plasticizer PG were selected as independent variables, whereas dependent variables are \% drug release in $20 \mathrm{~min}$, folding endurance and disintegration time. ${ }^{11,12}$ Formulations F1 to F9 were prared using three different levels of HPMC E-5 and PG concentration Shown in Table 1. The responses of the dependent variables were evaluated. The polynomial equations were generated for each responses using Design Expert Software (7.1.4) and intensive grid search was performed over the experimental domain to locate five optimum formulations (S1-S5). These five formulations were then formulated and used to validate the obtained polynomial equation model. The summary of the formulations is shown in Table 2 .

\section{Physical appearance and surface texture of film}


Films of each formulation were randomly selected and visually inspected for texture by feel or touch. ${ }^{2}$

\section{Thickness and Weight uniformity}

Thickness of film was assessed using a Micrometer screw gauge with a least count of $0.01 \mathrm{~mm}$ at different spots of films. Thickness was measured at five positions (central and the four corners) and the mean thickness was calculated for three randomly selected films. Each film was weighed individually on an analytical balance (Contech, CB-50) and the average weight was calculated. ${ }^{11}$

\section{Surface $\mathrm{pH}$ measurement}

Surface $\mathrm{pH}$ of 3 randomly selected films was determined to check whether the film causes irritation to oral mucosa using pH meter (Equip Tronics, EQ-614, India). In this method $\mathrm{pH}$ probe was placed in close contact with the wetted film surface and $\mathrm{pH}$ was recorded. ${ }^{10}$

\section{Moisture content}

The prepared films were weighed individually and kept in desiccators containing calcium chloride at room temperature for $24 \mathrm{hr}$. The films were weighed again, until constant weight is achieved. The $\%$ moisture content was calculated as a difference between initial and final weight with respect to final weight. ${ }^{13}$

$\%$ Moisture content $=\frac{\text { Initial weight }- \text { Final weight }}{\text { Initial weight }}$

\section{Disintegration time}

Disintegration time is calculated manually by dipping film in $10 \mathrm{ml}$ of Acetate buffer $\mathrm{pH} 4.5$ in a beaker with swirling every $10 \mathrm{sec}$. at $37 \pm 2^{\circ} \mathrm{C}$. When film starts to break or disintegrates, time was noted.

\section{Folding endurance}

Folding endurance of films was determined manually by repeatedly folding a film at the same place until it breaks. The experiments were performed in triplicate and average values were reported. ${ }^{12}$

\section{Tensile strength}

Tensile strength is defined as the maximum stress applied to a point at which the film specimen breaks and can be calculated by the applied load at rupture divided by the cross-sectional area of the strip as given in the equation below:

Tensile strength $=\frac{\mathrm{N}}{\mathrm{mm}^{2}}=\frac{\text { Load at failure } \times 100}{\text { Strip thickness } \times \text { Strip width }}$

Tensile strength of $400 \mathrm{~mm}^{2}$ randomly selected film was checked by Universal tensile strength testing machine
(LS5, Lloyd Instruments Limited, UK). The force of the film at the point when the film broke was recorded. ${ }^{14}$

\section{Drug content uniformity}

This was determined by standard assay method described for the PXT $\mathrm{HCl}$ in USP 28. Content uniformity was determined by estimating the API content $(10 \mathrm{mg})$ in individual strip. Limit of content uniformity is $85-115 \%$.

\section{In vitro drug release studies}

USP dissolution apparatus type II was used to study drug release from film under sink conditions at $37 \pm 0.5^{\circ} \mathrm{C}$ and $50 \mathrm{rpm}$. A single film was placed in $500 \mathrm{ml}$ dissolution media containing pH 4.5 Acetate buffer. ${ }^{5}$ Samples $(10 \mathrm{ml})$ were withdrawn at suitable time interval of 2, 4, 6, 8, 10 and 20 min and replenished with fresh dissolution medium. The amount of PXT was determined by UV spectrophotometer at $292.5 \mathrm{~nm}$ (Jasco) with the help of standard curve of drug the test was performed in triplicate for each formulation.

\section{Kinetics of drug release}

To understand the release patterns followed by drug from film matrix, all formulations were subjected to various mathematical kinetic models like Zero-order, Firstorder, Higuchi, Korsmeyer-Peppas. The model with the highest correlation coefficient was considered to be the best fitting one. ${ }^{10}$

\section{Ex vivo drug permeation studies}

The optimized formulation was subjected to permeation studies through the sheep oral mucosa using Franz diffusion cell. PXT being hydrophobic drug has high permeability through oral mucosa and hence no penetration enhancer was incorporated. A $6 \mathrm{~cm}^{2}$ film was placed on the oral mucosa. Receptor compartment contained $15.5 \mathrm{ml}$ while donor compartment was filled with $1 \mathrm{ml}$ of acetate buffer $\mathrm{pH} 4.5$. The cell contents were stirred using magnetic bead at $37 \pm 1{ }^{\circ} \mathrm{C}$. Aliquots of $1 \mathrm{ml}$ were withdrawn at regular intervals (every $2 \mathrm{~min}$ ) for $30 \mathrm{~min}$ and filtered. The amount of drug permeated was quantified using UV spectroscopic method of analysis with the help of standard curve of drug $\left(\mathrm{y}=0.009 \mathrm{x}+0.013, \mathrm{R}^{2}=0.996\right.$ and range $\left.10-60 \mathrm{ppm}\right)$ at $292.5 \mathrm{~nm}$. The graph of cumulative amount of PXT $(\mu \mathrm{g})$ permeated per unit of mucosal surface area $\left(\mathrm{cm}^{2}\right)$ against time (min) was plotted. Permeation flux (J, $\mu \mathrm{g} \mathrm{cm}^{-2} \mathrm{~min}^{-1}$ ), was calculated from this graph as the amount of PXT passing across $1 \mathrm{~cm}^{2}$ of the permeation membrane per unit time. ${ }^{12}$

\section{Histopathological study}


The final optimized formulation was subjected for oral mucosa sensitivity test. After completion of the diffusion experiment, oral mucosa was collected and repeatedly washed with acetate buffer $\mathrm{pH} 4.5$. Small portion of the tissue was fixed in 10\% buffered formalin solution and dehydrated. Sections were taken and stained with haematoxylin eosin (HE) and examined under digital microscope (Motic) to evaluate any histological changes in the epithelium and the adjacent connective tissue. Control oral mucosa was also treated and examined similarly. ${ }^{15}$

\section{Accelerated stability studies}

Stability studies were conducted according to ICH guidelines Q1A. The orodispersible films were wrapped in aluminium foil, packed in glass container and kept in stability chamber, at $40 \pm 0.5^{\circ} \mathrm{C}$ temperature and $75 \pm 5 \% \mathrm{RH}$ for 3 months respectively. After 1, 2 and 3 months, oral films were tested for changes in appearance, drug content, disintegration time (sec).

\section{RESULTS AND DISCUSSION}

\section{Taste Masking of Paroxetine $\mathrm{HCl}$}

Phase solubility profile between PXT and HP $\beta$-CD was observed at $37^{\circ} \mathrm{C}$. It was observed that as we go on increasing the concentration of HP $\beta$-CD there was increase in concentration of PXT which gives linear curve as shown in Figure 1 and this linear curve followed an $A_{L}$ type system according to Higuchi and Conners showing that soluble complexes were formed. Phase solubility analysis indicated the formation of first order soluble complexes. The stability constant (K1:1) $371.08 \mathrm{M}^{-1}$ was obtained which was found to be within the range of 50 and $2000 \mathrm{M}^{-1}$.

\section{A. Determination of drug content in PXT and HP $\beta C D$ inclusion Complex}

Drug content of freeze dried complex of HP $\beta$ - CD and PXT was found to be $94 \pm 0.5 \%$.

\section{$B$. In vitro dissolution study}

Figure 2 indicates that $96.63 \%$ drug release was shown by drug and HP $\beta$ - CD complex within $30 \mathrm{~min}$. Figure 2

\section{Confirmation of complexation}

\section{FTIR studies}

Freeze dried complex showed prominent peaks of the drug, but there was a reduction in peak intensity which was obscured by HP $\beta$-CD peak, conforming the formation of inclusion complexes. Data shown in Figure 3.

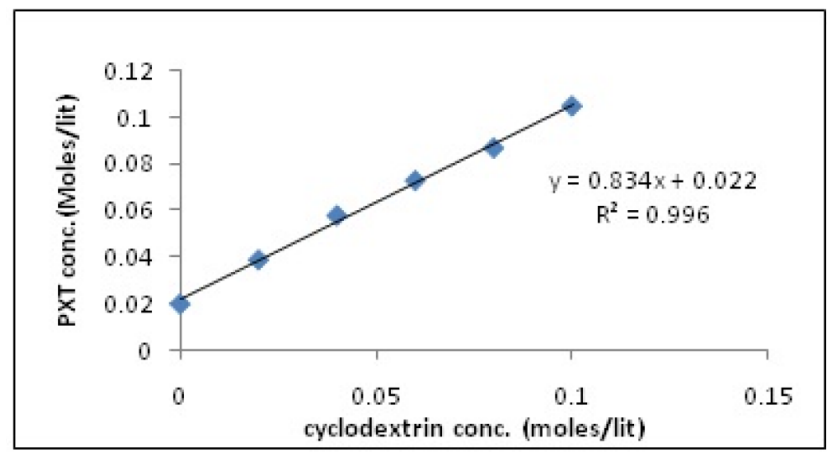

Figure 1: Phase solubility study between PXT and HP $\beta$-CD.

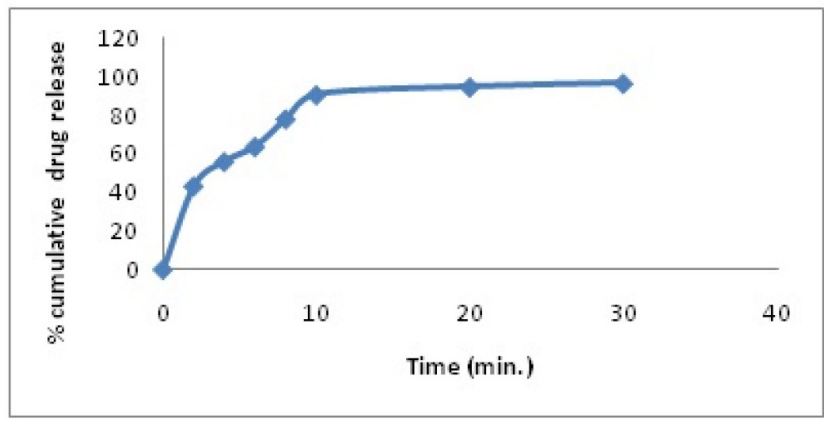

Figure 2: In vitro drug release of freeze dried complex of drug and $H P \beta-C D$.

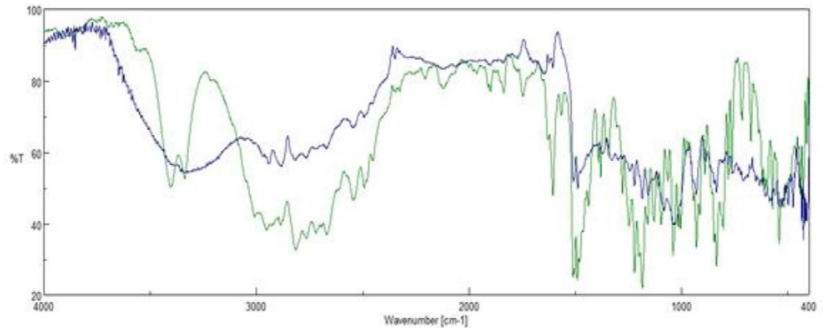

Figure 3: FTIR Overlay of PXT and freeze dried complex of PXT+ HP $\beta$ CD.

\section{XRPD studies}

XRD analysis was carried out to confirm the formation of amorphous solid state (inclusion complex formation). In which it has been observed that the diffraction patterns of inclusion complex are somewhat diffused compared to pure drug. The diffractogram of drug exhibited characteristic peaks, due to its crystalline nature. But in freeze dried complex (Figure 4), no characteristic peaks were observed due to amorphous nature of complex confirming the formation of inclusion complex.

\section{DSC study}

Thermogram of the complex showed very less intensity of peak of PXT at $138.5^{\circ} \mathrm{C}$ and sharp endothermic 
peak of $\mathrm{HP} \beta-\mathrm{CD}$ at $263.63^{\circ} \mathrm{C}$ as shown in Figure 5. This indicates successful inclusion complexation of drug with HP $\beta$-CD.

\section{Optimization of Formulation}

\section{Evaluation of taste masked orodispersible film}

\section{Physical Appearance}

All films were found to be smooth and elegant with transparent appearance.

\section{Thickness and Weight uniformity}

The average thickness of all ODFs ranged from $51-68 \mu \mathrm{m}$ as given in Table 3. This depicts that the film cast was uniform. Weight variation values (mg) of different PXT films were found to be in the range of 104-132 mg. Thus there was proportional gain in weight of films with increase in the thickness of films.
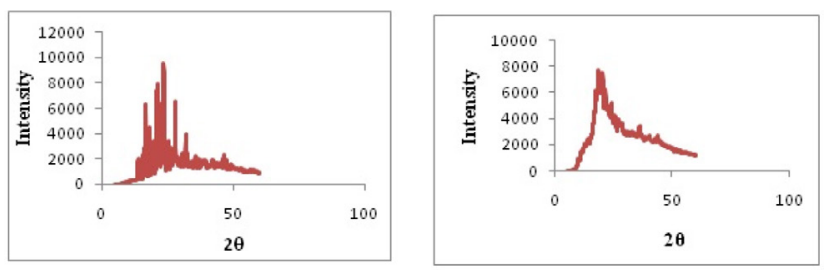

Figure 4: XRD graph of (a) Pure drug (b) Freeze dried complex of PXT and HP $\beta-C D$.

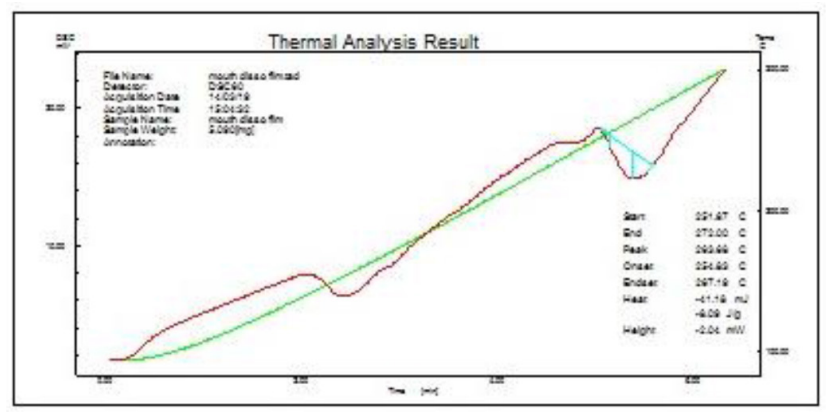

Figure 5: Thermogram of freeze dried drug and HP $\beta-C D$ complex.

\section{Surface pH measurement}

Surface $\mathrm{pH}$ of all the films was found to be in the range of that of 4.5- 4.8 (Table 3). Hence no mucosal irritation was expected from these films.

\section{Moisture content}

Results showed that moisture content of all films ranges from 3.26 to 5.6 .

\section{Folding Endurance}

Folding endurance was found to be increased with increasing concentration of PG. This may be due to increase in molecular mobility with the increase in PG concentration which in turns caused a reduction resistance and increase in flexibility. ${ }^{16}$

\section{Disintegration time}

Disintegration time calculated by simple manual method is shown in Table 4, which indicates that disintegration time of F2 to F6 batches was less than 30 sec. This could be because of less thickness and viscosity of these films containing low concentration of HPMC E-5. On the other hand F7 to F9 formulations containing high concentration of HPMC E-5 showed high D.T. irrespective of the concentration of PG.

\section{Drug Content Uniformity}

The percentage drug content was determined using the standard calibration curve. Results are shown in Table 4 As the drug content values of same formulation did not show a significant difference, it can be concluded that the drug was uniformly dispersed in ODF.

\section{Tensile strength}

Tensile strength of the film was checked by universal tensile strength testing machine. Typical tensile strength for film should be $1.80 \pm 0.20$ MPTensile strength of optimized batch $\mathrm{F} 3$ was found to be $9.12 \mathrm{~N} / \mathrm{mm}^{2}$,

\begin{tabular}{|c|c|c|c|c|}
\hline Formulation code & Thickness ${ }^{*}(\mu \mathrm{m})$ & Weight uniformity ${ }^{*}(\mathrm{mg})$ & Surface $\mathrm{pH}^{*}$ & Moisture content (\%) \\
\hline F1 & $53 \pm 1.24$ & $118 \pm 0.94$ & $4.48 \pm 0.01$ & 5.4 \\
\hline F2 & $52 \pm 1.14$ & $109 \pm 0.56$ & $4.38 \pm 0.01$ & 4.58 \\
\hline F3 & $51 \pm 1.54$ & $106 \pm 0.87$ & $4.38 \pm 0.02$ & 3.26 \\
\hline F4 & $56 \pm 1.42$ & $104 \pm 0.46$ & $4.36 \pm 0.05$ & 4.31 \\
\hline F5 & $58 \pm 1.10$ & $115 \pm 0.53$ & $4.36 \pm 0.02$ & 3.5 \\
\hline F6 & $58 \pm 1.08$ & $114 \pm 1.21$ & $4.37 \pm 0.01$ & 4.2 \\
\hline F7 & $65 \pm 0.96$ & $124 \pm 0.81$ & $4.37 \pm 0.03$ & 4.87 \\
\hline F8 & $63 \pm 1.63$ & $118 \pm 0.67$ & $4.36 \pm 0.03$ & 5.6 \\
\hline F9 & $68 \pm 1.29$ & $132 \pm 0.74$ & $4.37 \pm 0.02$ & 4.54 \\
\hline
\end{tabular}


Table 4: Folding endurance, Disintegration time and drug content uniformity of F1- F9 formulations

\begin{tabular}{|c|c|c|c|}
\hline $\begin{array}{c}\text { Formulation } \\
\text { Code (FC) }\end{array}$ & $\begin{array}{c}\text { Folding } \\
\text { endurance* }\end{array}$ & $\begin{array}{c}\text { Disintegration } \\
\text { time }(\mathbf{s e c} .)\end{array}$ & $\begin{array}{c}\text { Drug content } \\
\text { uniformity* (mg) }\end{array}$ \\
\hline F1 & $62 \pm 0.45$ & $38 \pm 1.53$ & $9.49 \pm 0.01$ \\
\hline F2 & $68 \pm 1.00$ & $23 \pm 0.81$ & $9.50 \pm 0.02$ \\
\hline F3 & $72 \pm 1.52$ & $24 \pm 1.2$ & $9.49 \pm 0.03$ \\
\hline F4 & $43 \pm 1.52$ & $30 \pm 0.88$ & $9.48 \pm 0.01$ \\
\hline F5 & $49 \pm 1.52$ & $28 \pm 1.89$ & $9.50 \pm 0.01$ \\
\hline F6 & $52 \pm 1.52$ & $30 \pm 1.54$ & $9.51 \pm 0.01$ \\
\hline F7 & $24 \pm 1.52$ & $39 \pm 1.11$ & $9.48 \pm 0.03$ \\
\hline F8 & $28 \pm 1.08$ & $40 \pm 1.63$ & $9.49 \pm 0.01$ \\
\hline F9 & $34 \pm 0.51$ & $45 \pm 1.12$ & $9.50 \pm 0.02$ \\
\hline
\end{tabular}

which means formulation F3 showed good mechanical strength so as to withstand any damage during handling or transportation. ${ }^{16}$

\section{In-vitro drug release studies}

In-vitro drug release profiles are shown in Figure 6. An immediate drug release was successfully observed for all taste masked orodispersible films of PXT. Optimized batch F3 showed maximum cumulative drug release in 20 min. Minimum drug release was shown by F7 formulation containing high concentration of HPMC E -5 and lowest concentration of PG (Table 5). Thus, in-vitro drug release study result showed that as the concentration of plasticizer increases, drug release of mouth dissolving films also increases.

\section{Kinetics of Drug Release}

The value of coefficient of regression for different models of optimized formulation (F3) is given in Table 6. The coefficient of regression value was found to be highest for First order model and hence the release mechanism was found to follow first order kinetics.

\section{Ex vivo drug permeation studies}

The optimized formulation F3 was subjected to permeation studies through the sheep oral mucosa. Results of ex vivo drug permeation studies are shown in Table 7 . Cumulative drug release of $\mathrm{F} 3$ batch was found to be $65.69 \%$ at the end of $30 \mathrm{~min}$. (Figure 7).

\section{Histopathological study}

The final optimized formulation F3 was subjected to oral mucosa sensitivity test. Histopathological evaluation of sections of sheep oral mucosa showed (Figure 8) that cellular membrane was intact and there was no damage to the epithelial layer. Cell necrosis was not observed and hence it can be concluded that, formulation F3 is safe for oral administration of PXT through orodispersible film.

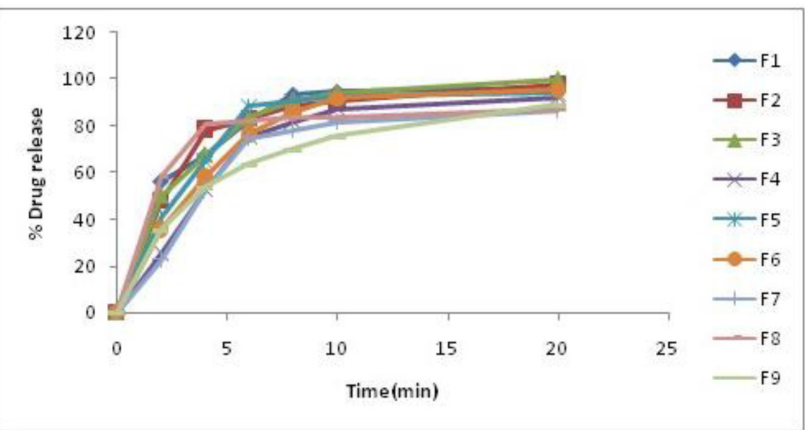

Figure 6: Comparative in vitro drug dissolution profiles of PXT orodispersible films.

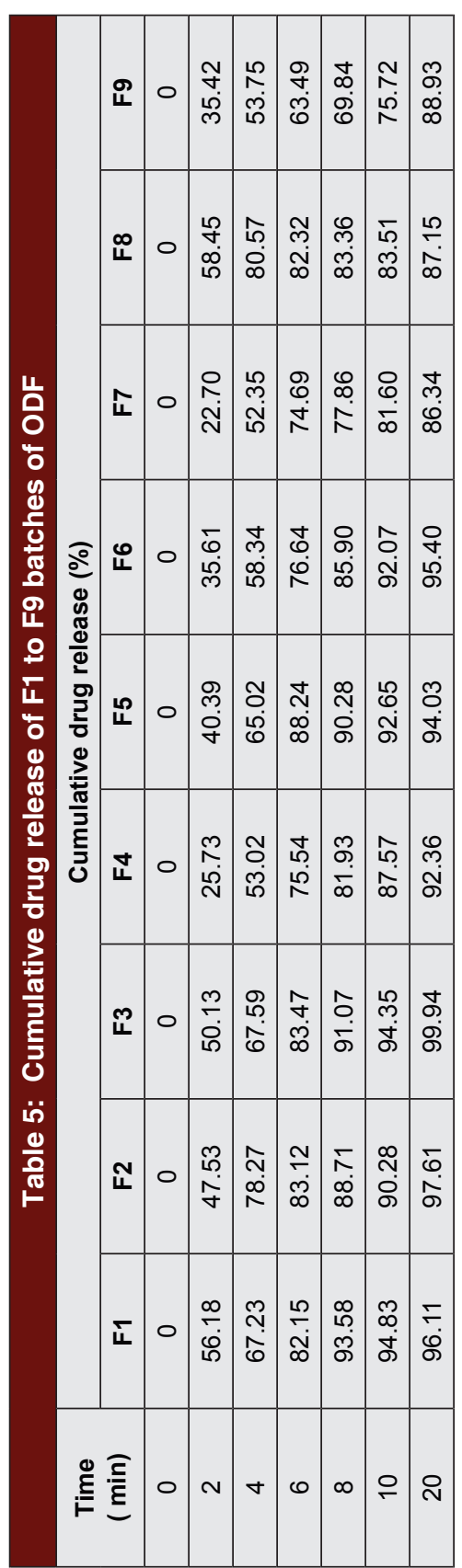




\begin{tabular}{|c|c|c|c|c|c|c|}
\hline \multicolumn{6}{|c|}{ Table 6: Kinetic parameters of PXT orodispersible film } \\
\hline \multirow{2}{*}{ FC } & $\begin{array}{c}\text { Zero } \\
\text { order }\end{array}$ & $\begin{array}{c}\text { First } \\
\text { order }\end{array}$ & Higuchi & $\begin{array}{c}\text { Hixon- } \\
\text { crowel }\end{array}$ & $\begin{array}{c}\text { Korsmeyer- } \\
\text { Peppas }\end{array}$ \\
\cline { 2 - 7 } & $r^{2}$ & $r^{2}$ & $r^{2}$ & $r^{2}$ & $r^{2}$ & $N$ \\
\hline F3 & 0.6241 & $\mathbf{0 . 9 9 5 1}$ & 0.8835 & 0.6845 & 0.9895 & 0.2059 \\
\hline
\end{tabular}

\begin{tabular}{|c|c|}
$\begin{array}{c}\text { Table 7: Ex vivo permeation of PXT through oral } \\
\text { mucosa }\end{array}$ \\
\hline Time (min) & cum\% drug release \\
\hline 0 & 0 \\
\hline 2 & 0.00 \\
\hline 4 & 2.30 \\
\hline 6 & 15.97 \\
\hline 8 & 23.70 \\
\hline 10 & 48.86 \\
\hline 20 & 62.81 \\
\hline 30 & 65.69 \\
\hline
\end{tabular}

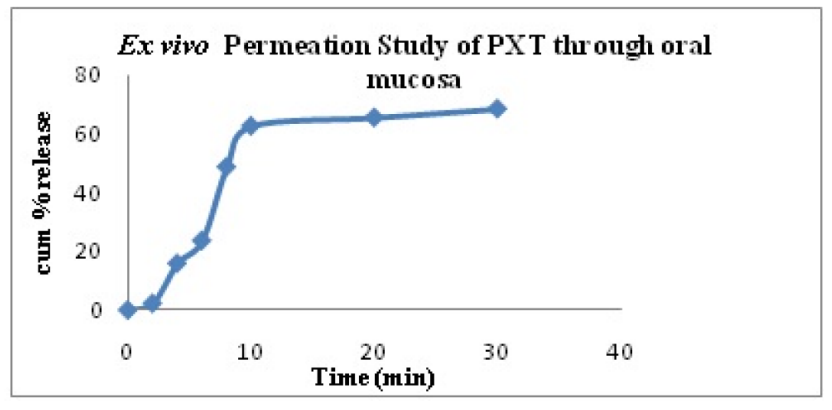

Figure 7: EX vivo permeation of PXT through oral mucosa.
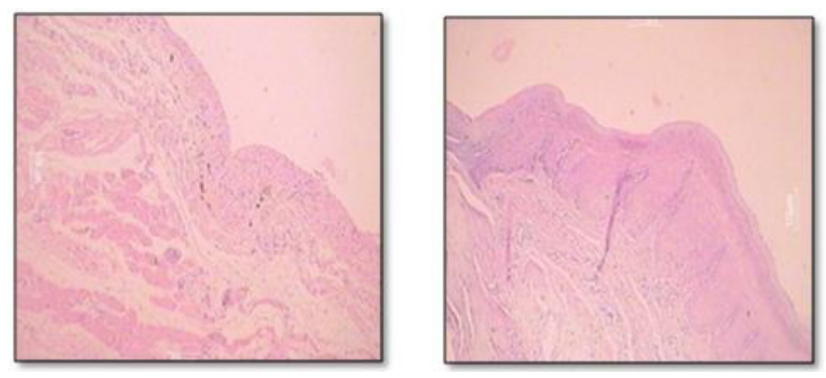

Figure 8: Histopathological evaluation of sections of sheep oral mucosa (a) Control (b) Sample mucosa (treated formulation F3).

\section{Accelerated Stability Studies}

The results of stability studies performed on batch F3 are shown in Table 8 . After the 3 months study, it was found that there was no change in appearance of the film and negligible change in moisture content. The drug content and \% drug release after 20 min. was decreased but not significantly.
Table 8: Stability studies of optimized batch F3 at $40^{\circ} \mathrm{C} \pm 2{ }^{\circ} \mathrm{C}$ and $75 \% \pm 5 \mathrm{RH}$

\begin{tabular}{|c|c|c|c|c|}
\hline Parameters & $\mathbf{0}$ day & $\mathbf{3 0}$ days & $\mathbf{6 0}$ days & $\mathbf{9 0}$ days \\
\hline Appearance & $\begin{array}{c}\text { No } \\
\text { change }\end{array}$ & $\begin{array}{c}\text { No } \\
\text { change }\end{array}$ & $\begin{array}{c}\text { No } \\
\text { change }\end{array}$ & $\begin{array}{c}\text { No } \\
\text { change }\end{array}$ \\
\hline Drug content $(\mathbf{m g})$ & 9.38 & 9.36 & 9.35 & 9.31 \\
\hline \% Drug release & 96.092 & 95.64 & 95.32 & 95.21 \\
\hline $\begin{array}{c}\text { Disintegration } \\
\text { time(min.) }\end{array}$ & 24 & 25 & 25 & 25 \\
\hline
\end{tabular}

\section{CONCLUSION}

Paroxetine hydrochloride a bitter drug could be successfully taste-masked using HP $\beta$-CD by freezedrying method and was incorporated to prepare of oro-dispersible films. Films formulated with HPMC E-5 (59\%), PG (36\%) and PVP K-30 (10\%) as superdisintegrant showed faster disintegration and drug release. The prepared formulation offered significant results in terms of improving taste and bioavailability.

In the final conclusion, taste masked PXT orodispersible films can be successfully formulated, to provide rapid release using HP $\beta$-CD as taste masking agent, PVP K-30 as superdisintegrant and makes it suitable for the anxiolytic and depressed patients, those who are suffering from dysphasia and also for bedridden patients.

\section{ACKNOWLEDGEMENT}

I am thankful to Dr. K.G. Bothara, Prinicipal, STES'S Sinhgad Institute of Pharmacy, Narhe, Pune for providing facilities and constant support for completion of this research work.

\section{CONFLICT OF INTEREST}

The authors declare no conflict of interest.

\section{ABBREVIATIONS}

ODF: Orodispersible film; PXT HCl: Paroxetine Hydrochloride; DSC: Differential Scanning Calorimetry; ICH: International Conference on Harmonization; FT-IR: Fourier Transformed-Infrared Spectroscopy; HCl: Hydrochloric Acid; HPLC: High Performance Liquid Chromatography; $\lambda_{\text {max }}$ : Maximum Absorbance; RH: Relative Humidity; UV: Ultra Violet; USP: United States Pharmacopoeia; PVA: Polyvinyl alcohol; HPMC: Hydroxy propyl methyl cellulose; PVP: Poly vinyl pyrolidone; SSG: Sodium Starch Glycolate; PEG: Polyethylene glycol; HP $\beta$-CD: Hydroxy propyl beta cyclodextrin. 


\section{REFERENCES}

1. Nagaraju T, Gowthami R, Rajashekar M, Sandeep S, Mallesham M, Sathish D, et al. Comprehensive review on oral disintegrating films. Curr Drug Deliv. 2013;10(1):96-108.

2. Dixit RP, Puthli SP. Oral strip technology: Overview and future potential. J Control Release. 2009;139(2):94-107.

3. Siddiqui N, Garg G, Sharma PK. A novel approach in oral fast dissolving drug delivery system and their patents. Adv Biol Res. 2011;5(6):291-303.

4. Morales JO, Jason T. Manufacture and characterization of mucoadhesive buccal films. Eur J Pharm Biopharm. 2011;77(2):187-99.

5. Jagdale SC, Gawali VU, Kuchekar BS, Chabukswar AR. Formulation and in vitro evaluation of taste-masked oro-dispersible dosage form of diltiazem hydrochloride. Brazilian J Pharma Sci. 2011;47(4):907-16.

6. Sumitha C, Karuna SN, Divya B, Madhavi K, Varma M. Taste masking of ondansetron hydrochloride by polymer carrier system and formulation of rapid-disintegrating films. Int J Chem Res. 2009;1(2):24-7.

7. Natarajan R, Vaishnani R, Rajendran NN. Formulation and evaluation of immediate release tablets of Paroxetine $\mathrm{HCl}$ using different superdisintegrants. Int J Res Pharma Biomed Sci. 2011;2(3):1095-9.

8. Patel HV, Patel NV, Patel NK. In-vitro characterization of matrix type transdermal drug delivery systems of Paroxetine hydrochloride using different plasticizers. Int J Res in Pharm Chem. 2013;3(2):345-53.
9. Bande SV, Kasture PV, Vaidya V. Development of mouth dissolving film of verapamil hydrochloride: Effect of formulation variables. Int J Pharma Bio Sci. 2013;2(4):348-57.

10. Shiledar RR, Tagalpallewar AA, Kokare CR. Formulation and in vitro evaluation of xanthan gum-based bilayered mucoadhesive buccal patches of Zolmitriptan. Carbohydrate Polymers. 2014;101:1234-42.

11. Bhalekar MR, Mirajkar R, Kokare D. Formulation and optimization of mouth dissolving films of lornoxicam using drug resin complex. Int $J$ Univers Pharm Life Sci. 2013;3(3):39-58.

12. Chaudhary H, Gauri S, Rathee P, Kumar V. Development and optimization of fast dissolving Oro dispersible films of Granisetron $\mathrm{HCl}$ using BoxBehnken statistical design. Bulletin of Faculty of Pharmacy, Cairo University. 2013;51(2):193-201.

13. Panchal MS, Patel H, Bagada A, Vadalia KR. Formulation and evaluation of mouth dissolving film of Ropinirole Hydrochloride by using pullulan polymers. Int J Pharma Res Alli Sci. 2012;1(3):60-72.

14. Morales JO, Jason T. Manufacture and characterization of mucoadhesive buccal films. Eur J Pharm Biopharm. 2011;77(2):187-99.

15. Jelvehgari $M$, Valizadeh $H$, Motlagh $R J$, Montazam $H$. Formulation and physicochemical characterization of buccoadhesive microspheres containing diclofenac sodium. Adv Pharm Bull. 2014;4(3):295-301.

16. Galgatte UC, Khanchandani SS, Jadhav YG, Chaudhari PD. Investigation of different polymers, plasticizers and super disintegrating agents alone and in combination for use in the formulation of fast dissolving oral films. Int J Pharm Tech Res. 2013;5(4):1465-72.

\section{PICTORIAL ABSTRACT}

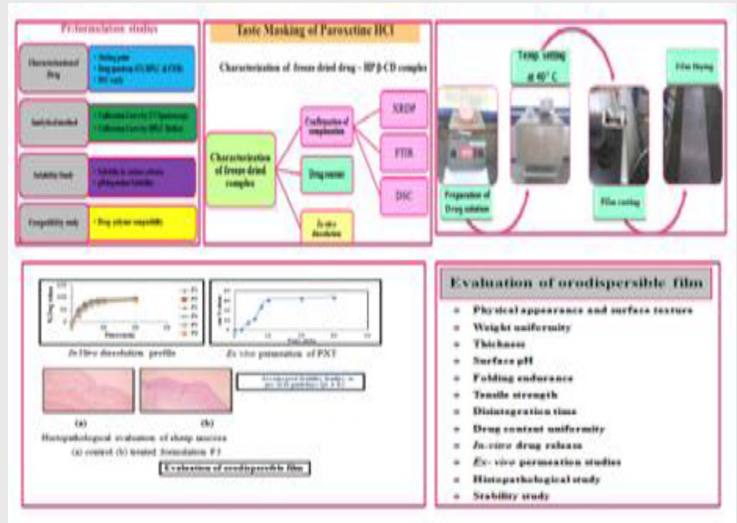

\section{SUMMARY}

Bitter taste of PXT was masked by using HP $\beta$ - CD. Optimization of orodispersible film was carried out using $3^{2}$ factorial design. The final optimized formulation was then tested for oral mucosa sensitivity, the results indicated that the selected formulation batch F3 not showing any irritation effect on oral mucosa of sheep. The stability studies of final optimized formulation revealed that was no significant change in the physical parameters.

\section{About Authors}

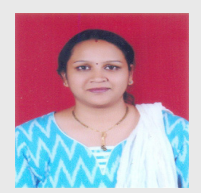

Dr. (Mrs.) Swapnila V Shinde is currently an Assistant Professor in the Department of Pharmaceutics at STESs Sinhgad Institute of Pharmacy, Narhe, Pune. She has total 13 years of teaching experience. She has authored two text books for first year B.Pharmacy students. She is recipient of Dr. R. L. Nicore award for best research article in the field of Pharmaceutics.

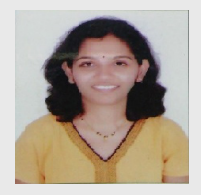

Shraddha Phatak, Postgraduate student of Sinhgad Institute of Pharmacy, Narhe, Pune from Department of Pharmaceutics. 
Ganesh Awale is a student of Department of Pharmaceutics at Sinhgad Institute of Pharmacy, Narhe, Pune.

Supriya Nikam, Assistant Professor at Sinhgad Institute of Pharmacy, Narhe, Pune at Department of Pharmaceutics won various state level post presentation competitions.

Cite this article: Shinde SV, Phatak S, Awale G, Nikam S. Development of Taste Masked Orodispersible Film Containing Paroxetine Hydrocloride. Indian J of Pharmaceutical Education and Research. 2020;54(2s):s98-s107. 